\title{
Optimalisasi Keamanan Jaringan Menggunakan Metode Port Knocking Pada LAZIS Wahdah Jakarta
}

\author{
Ismanto $^{1}$, Aristejo ${ }^{2}$
}

\begin{abstract}
Network security system is very important, because it relates to the security of resources in network, if the network security system is weak, so people are not interested could be easy to attacks on the system, either to manipulate the data or changing the configuration of the network. In Lazis Wahdah has not made the block on port network systems, and used of modem Asymmetric Digital Subscriber Line (ADSL) in the network do not block the port. This is because the ADSL Modem just can do simple configuration and also not have features such as Router. Focusing on the issue, the use of methods Port Knocking on Mikrotik RB951UI-2ND is an appropriate way to improve network security system. With Port Knocking only IP address that corresponds to the rule or according to a predetermined Knock can access Mikrotik, while that does not comply with the rule will remain blocked. So Port Knockingmethod can improve the security system on the network at Lazis Wahdah Jakarta.
\end{abstract}

Intisari- Keamanan sistem jaringan sangat penting, karena berkaitan dengan keamanan sumber daya yang ada pada jaringan berupa data-data, jika system keamanan jaringan lemah,maka orang yang tidak berkepentingan dapat dengan mudah melakukan serangan pada sistem tersebut,baik untuk melakukan manipulasi data atau merubah konfigurasi pada jaringan. Di Lazis Wahdah Jakarta belum melakukan blok pada port system jaringan, dan penggunaan modem Asymmetric Digital Subscriber Line (ADSL) pada jaringaan tidak melakukan blok terhadap port, ini karena Modem ADSL hanya bisa melakukan konfigurasi sederhana dan juga tidak memilik ifitur seperti halnya Router. Berfokus pada masalah tersebut, penggunaan metode Port Knocking pada Mikrotik RB941-2ND merupakan cara yang tepat untuk meningkatkan sistem keamanan jaringan. Dengan Port Knocking hanya IP Address yang sesuai dengan rule atau sesuai dengan Knock yang telah ditentukan yang dapat mengakses ke Mikrotik, sementara yang tidak sesuai dengan rule akan tetap diblok. Sehingga metode Port Knocking dapat meningkatkan system keamanan pada jaringan Lazis Wahdah Jakarta.

Kata Kunci-Mikrotik, Winbox, Secure Shel (SSH), Firewall, Port Knocking.

\section{PENDAHULUAN}

Keamanan jaringan komputer atau Computer Network Security sangat berhubungan dengan keamanan data, oleh karena itu keamanan jaringan sangat penting untuk melindungi data dari berbagai serangan dari pihak - pihak yang tidak bertanggung jawab. Serangan tersebut dapat di tujukan terhadap instansi, perusahaan atau lembaga tertentu, tidak terkecuali Lembaga Lazis Wahdah Islamiyah yang notabenya jenis Yayasan atau lembaga dapat mengalami hal

\footnotetext{
1,2Jurusan Teknik Informatika, STMIK Antar Bangsa, Jl. HOS Cokroaminoto, Kawasan Bisnis CBD Ciledug, Blok A5 No 29-36, Karang Tengah, Tangerang 15157, tlp: 021-50986099; e-mail: daqu.ismanto@gmail.com, aristejo@antarbangsa.ac.id
}

tersebut. Serangan bisa saja bertujuan untuk mendapatkan sumber daya tertentu, merubah konfigurasi sistem jaringan yang ada, memanipulasi data misalnya mengakses Server untuk merubah data donatur beserta perolehannya yang berada pada sistem. Serangan tersebut dapat berupa Snifffer, FTP Attack, DOS (Denial Of Sevice Attack) dan lainya.

Serangan dilalukan melalui celah-celah yang ada pada jaringan komputer, dan salah satunya melalui port - port yang dalam keadaan terbuka, sehingga nantinya akan membuat orang - orang yang tidak mempunyai hak akses maupun yang tidak berkepentingan dapat dengan mudah mengendalikan port - port yang telah ia akses. Di Lazis Wahdah Islamiyah sistem keamanan jaringan masih sebatas menggunakan Service Set Identifier (SSID) pada modem Asymmetric Digital Subcriber Line (ADSL), menurut penulis hal ini masih rentan terhadap serangan, karena port pada jaringan tetap terbuka terbukti dengan hanya dengan memasukan IP Address modem ADSL melalui Browser atau HTTP (port 80), SSH (22), atau Telnet (23) maka akan langsung tampil interface login ke modem ADSL. Permasalahan yang dialami di Lazis Wahdah Islamiyah adalah tampilan interface login modem ADSL yang mudah di akses oleh penyusup, sehingga dengan memasukan user dan password default modem ADSL, penyusup dapat masuk dan melakukan perubahan sistem jaringan yang ada. Modem Indihome sangat rentan sekali diakses konfigurasinya melalui web browser dalam satu jaringan yang sama, karena memang sering kita temukan konfigurasi untuk login ke modem Indihome sangat mudah di akses, kita bisa mencari di internet username dan password modem indihome dari beberapa modem Indihome yang sering ditemukan diantaranya Modem GPON HG6243C, Modem Huawei HG8245A, Modem Huawei HG8245H, Modem ZTE F609, Modem ZTE F660 dan Modem ZTE h108n.

Salah satu metode untuk mengatasi serangan terhadap port - port pada sistem jaringan komputer ialah dengan metode Port Knocking [1]. Port Knocking merupakan suatu sistem keamanan yang dibuat secara khusus untuk sebuah jaringan. Pada dasarnya cara kerja dari port knocking adalah menutup port yang ada seperti Winbox (8291), SSH (22), Telnet (23) dan HTTP (80). Dan hanya user tertentu saja yang dapat mengakses port yang telah ditentukan, yaitu dengan cara mengetuk atau mengirim paket tertentu terlebih dahulu. Berbeda dengan cara kerja dari Firewall, cara kerja dari Firewall adalah menutup semua port tanpa memperdulikan apapun meskipun user tersebut memiliki hak untuk mengakses port tersebut, sehingga user yang tidak memiliki hak akses tersebut juga tidak bisa untuk mengaksesnya. Sedangkan Port Knocking meskipun port yang ada telah ditutup, tetapi user yang memiliki hak akses dan mengetahui rule atau Knock untuk membuka port maka user tersebut tetap dapat mengakses port tersebut dan masuk ke dalam sistem jaringan. 
Dalam penelitian ini, penyusun mencoba mengimplementasikan sistem keamanan jaringan komputer dengan menggunakan metode Port Knocking pada Mikrotik RB941-2ND-TC HAP Lite untuk meningkatkan sistem keamanan jaringan di Lazis Wahdah Islamiyah.

Permasalahan pada penelitian ini yang terdapat pada sistem jaringan di Lembaga Lazis Wahdah Islamiyah adalah Sistem keamanan masih ada celah pada port jaringan. Computer port jaringan selalu terbuka.

Adapun Ruang Lingkup pada Sistem Keamanan Jaringan Komputer ini adalah hanya menggunakan metode PortKnocking pada Mikrotik RB941-2ND-TC HAP Lite untuk meningkatkan sistem keamanan jaringan komputer dengan studi kasus di Lazis Wahdah Islamiyah Jakarta. Sedangkan tujuan dilakukannya penelitian ini adalah : 1) Berbagi informasi dan tips untuk memahami, menjalankan, dan mengelola keamanan jaringan computer, 2) Memahami manfaat metode port knocking, antara lain: dapat meningkatkan kestabilan sistem keamanan pada jaringan komputer dan dengan metode Port Knocking Administrator akan lebih aman pada saat melakukan perubahan konfigurasi pada sistem jaringan.

\section{TINJAUAN PUSTAKA}

Sistem keamanan komputer menggunakan Port Knocking sebagai metode autentikasi, seorang administrator dapat meningkatkan sistem keamanan komputer dari serangan Brute Force yang ditujukan untuk berbagai layanan seperti SSH Server, FTP Server, dan MySQL Server [2].

Knock bertugas sebagai port knocking daemon yang akan menerima autentikasi port knocking dari user dan akan menulis ulang firewall agar user tersebut dapat melakukan koneksi kelayanan seperti SSH, FTP dan MySQL server. IP Tables dan Uncomplicated Firewall(UFW) digunakan untuk membangun firewall akan menolak semua koneksi menuju layanan SSH, FTP, dan MySQL server. Jika user mencoba mengakses layanan SSH, FTP atau MySQL tanpa melakukan autentikasi maka firewall akan menolak koneksi tersebut, dan bila user melakukan autentikasi port knocking dengan mengirimkan paket SYN ke port yang telah ditetapkan dalam port knocking daemon, maka port knocking daemon akan menulis ulang firewall sehingga user dapat mengakases layanan SSH, FTP dan MySQL Server.

Intergritas keamanan dewasa isi sangatlah penting untuk ditingkatkan, celah-celah keamanan yang terdapat pada jaringan dapat dilihat oleh orang yang tidak bertanggung jawab dan dapat menjadi ancaman yang patut diperhatikan.Berhubungan dengan hal itu, administrator jaringan dituntut berkerja lebih untuk dapat mengamankan jaringan komputer yang dikelolanya. Salah satu bentuk keamanan jaringan yang sering digunakan oleh seorang administrator jaringan dalam pengelolaan server yaitu melalui remote login seperti Secure Shell (SSH) [3]

Prinsip dasar dari SSH yaitu membuka terus port (22) tempat SSH server berada, lalu administrator jaringan akan melakukan login kedalam port tersebut yang selanjutnya port SSH akan terbuka dan komunikasi dapat dilakukan antara client dengan server.Port SSH yang selalu terbuka merupakan suatu celah keamanan jaringan yang dapat digunakan oleh orang yang tidak bertanggung jawab untuk masuk kedalam server. Dengan menggunakan serangan Brute force yang sudah dimodifikasi dengan multi threading, maka seseorang dapat melakukan percobaan penebakan password SHH sampai 1000 kali dalam sekali percobaan penebakan.

Berfokus pada permasalahan tersebut, pada penelitian ini, Random Port Knocking merupakan cara yang tepat dan dapat dipakai untuk meningkatkan keamanan pada port SSH. Dengan Random Port Knocking maka port SSH akan dibuka sesuai dengan kebutuhan sehingga serangan Brute force dapat dihindari dan stabilitas keamanan jaringan dapat lebih ditingkatkan.

Dari hasil penelitian ini saya menyimpulkan bahwa penggunaan metode Port Knocking pada jaringan akan membuat stabilitas keamanan jaringan lebih meningkat, karena untuk mengakses port tertentu harus melakukan autentikasi yang telah ditentukan berupa knock atau paket, dan bila knock atau paket salah maka port tidak akan terbuka dan jika benar maka port akan terbuka sehingga dapat diakses.

\section{METODE PENELITIAN}

Metode penelitian yang digunakan dalam penelitian ini adalah sebagai berikut.

A. Analisa Penelitian

Analisa penelitian data yang dilakukan pada penelitian ini meliputi:

1. Study literature

Study literature dilaksanakan dengan cara mengumpulkan dan mempelajari buku-buku, jurnal-jurnal dan artikelartikel di internet yang berhubungan dengan jaringan komputer, PortKnocking dan Mikrotik Routerboard.

2. Desain Sistem

Pada tahap ini dilaksanakan perancangan sistem yang akan dibuat berdasarkan hasil study literature yang ada. Perancangan sistem ini meliputi desain topologi jaringan dan konfigurasi sistem.

3. Testing

Pada tahap ini dilakukan uji coba sistem untuk mencari masalah yang mungkin timbul, dan mengevaluasi jalannya sistem.

4. Analisa Hasil Testing

Pada tahap ini dihasilkan uji coba dan beberapa revisi, jika terjadi kekurangan dan kesalahan yang terjadi. Diharapkan sistem tersebut mengalami segala macam uji coba sehingga menghasilkan output yang diharapkan.

5. Implementasi

Dalam tahap ini, dilakukan implementasi berdasarkan studi pustaka dan rancangan yang telah dibuat pada tahap sebelumnya.

6. Pembuatan Laporan

Pada tahap terakhir ini disusun laporan sebagai dokumentasi dari pelaksanaan penelitian. 
B. Metode Pengumpulan Data

Metode pengumpulan data yang dilakukan pada penelitian ini meliputi:

1. Metode Observasi

Melalui metode ini penulis melakukan observasi langsung pada Lazis Wahdah, observasi dilakukan guna melihat langsung keadaan Lazis Wahdah.

2. Metode Wawancara

Penelitian ini dilakukan langsung dengan cara tanya jawab dengan Ustadz Yudi Wahyudi ST, yang ada di Lazis Wahdah. Penelitian ini dilakukan untuk memperoleh data yang lebih detail.

3. Studi Pustaka

Yaitu dengan mengumpulkan berbagai sumber-sumber referensi baik berupa buku, artikel, jurnal dan sumbersumber lainnya sebagai acuan dalam implementasi keamanan jaringan komputer menggnakan metode port knocking.

\section{IV.HASIL DAN PEMBAHASAN}

A. Analisa Jaringan Berjalan

1. Analisa Hardware

Dari hasil analisa di Lazis Wahdah Islamiyah terdapat beberapa hardware sebagai pendukung sistem komputer jaringan yang berjalan, hardware hasil analisa sebagai mana pada table di bawa ini.

TABEL 1

PERANGKAT HARDWARE JARINGAN BERJALAN

\begin{tabular}{cllll}
\hline NO & \multicolumn{1}{c}{ Perangkat } & \multicolumn{1}{c}{ Merk } & \multicolumn{1}{c}{ Model } & Jumlah \\
\hline 1 & CPU & LG & SPC & 4 Unit \\
\hline 2 & Wireless Modem & Indihome & HG6243C & 1 Unit \\
\hline 3 & $\begin{array}{l}\text { Wireless } \\
\text { Router }\end{array}$ & Tp- LINK & TL- & 4 Unit \\
& & WN821N & \\
\hline 4 & $\begin{array}{l}\text { Kabel Fiber } \\
\text { Optik }\end{array}$ & SC-UPC & G657 & 1 Unit \\
& & & & \\
\hline
\end{tabular}

2. Analisa Software

Dari hasil analisa di Lazis Wahdah Islamiyah saya mendapati beberapa software yang mendukung sistem komputer yang berjalan, dan berikut pada table software tersebut.

TABEL 2

SOFTWARE PENDUKUNG JARINGAN

\begin{tabular}{|c|l|l|}
\hline NO & \multicolumn{1}{|c|}{ Software } & \multicolumn{1}{|c|}{ Kegunaan } \\
\hline 1 & Windows 8.1 Pro & OS Pada CPU \\
\hline 2 & Microsoft Office & $\begin{array}{l}\text { Software untuk buat } \\
\text { dokumen }\end{array}$ \\
\hline
\end{tabular}

3. Skema Jaringan

Penggunaan Jaringan komputer merupakan suatu hal yang penting untuk mendapatkan kinerja yang optimal dalam berkomunikasi dan mentransmisikan informasi antar komputer atau perangkat yang terhubung dengan jaringan. Jaringan komputer yang diterapkan Lazis Wahdah di Jalan
Raya Pasar Minggu No. 5L Jakarta Selatan adalah Wireless Local Area Network (WLAN). Kebutuhan akan jaringan komputer pada Lazis Wahdah digunakan untuk berbagai fungsi, diantaranya adalah :

a. Untuk pertukaran informasi

b. Berbagi pakai file

c. Pemakaian secara bersama sumber daya komputer

d. Pemakaian akses internet secara bersama

e. Pemakaian perangkat keras seperti printer secara bersama

Maka untuk menghubungkan jaringan antara komputer yang terpasang pada Lazis Wahdah dengan menggunakan Wireless Adapter, dan telah dibentuk suatu jaringan komputer Wireless Local Area Network (WLAN). Wireless Adapter yang dipakai untuk jaringan komponen Wireless Local Area Network (WLAN) di Lazis Wahdah merupakan komponen jaringan komputer yang berfungsi untuk menerima signal dari Wireless Modem.



Gbr 1. Skema Topologi Jaringan yang sedang berjalan

\section{Keamanan Jaringan}

Dari hasil analisa terhadap sistem jaringan Lazis Wahdah Islamiyah masih kurangnya tingkat keamanan yang ada, dimana untuk memanage jaringan menggunakan sebatas Wireless Modem Fiberhome. Wireless Modem Fiberhome memiliki kekurangan karena tidak memiliki fitur yang sederhana tidak seperti router, sehingga untuk konfigurasi jaringan kurang maksimal. Penggunaan Firewall pada modem juga kurang maksimal karena Port seperti HTTP (80), SSH (22) dan 23 (Telnet ) pada jaringan tetap terbuka.

B. Rancangan Sistem Jaringan Usulan

1. Manajemen Jaringan Usulan

Tidak ada perubahan secara signifikan pada topologi jaringan, hanya dengan menambahkan Mikrotik RB941-2ND, sebagai pengatur dalam jaringan dan juga untuk pendukung dari metode keamanan Port Knocking, sehingga topologi tetap menggunakan topologi Star. 


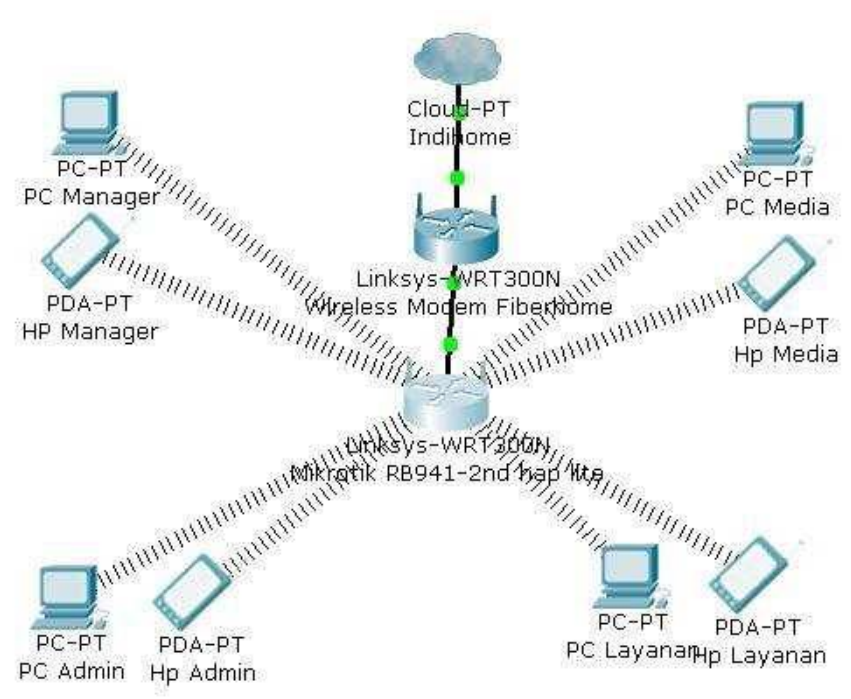

Gbr 2. Skema Jaringan Usulan

\section{Keamanan Jaringan}

Pada sistem keamanan jaringan komputer penambahan Mikrotik RB941- 2ND Hap Lite pada sistem jaringan, dapat membantu meningkatkan keamanan yang sebelumnya tidak ada keamanan jaringan pada modem wireless fiberhome,sekarang dirubah dengan meggunakan metode Port Knocking pada Mikrotik RB941-2ND. Karena dengan metode ini setiap tindakan yang berupaya mengakses port untuk login ke Mikrotik akan diautentikasi dengan knock yang telah ditentukan sebelumnya, dan keamanan pada jaringan diharapkan lebih baikdari sebelumnya.

\section{Usulan Pemecahan Masalah}

Pada usulan sistem jaringan Lazis Wahdah Islamiyah ada beberapa perubahan yang kiranya dapat meningkatkan keamanan, perubahan yang dimaksud ialah baik pada hardware atau pun konfigurasi dari jaringan tersebut.

1. Hardware

Perubahan hardware pada sistem jaringan yaitu dengan menambahkan Mikrotik RB941-2ND Hap lite , sebagai media untuk melakukan manajemen dan meningkatkan sistem keamanan jaringan komputer dari sebelumnya, sementara modem Fiberhome masih sederhana dan tidak memiliki fungsi yang lengkap untuk melakukan manajemen pada jaringan.

2. Software

Software yang akan digunakan untuk mengkonfigurasi Mikrotik RB941_2ND menggunakan Winbox-3.RC6, karena dengan Winbox Router ditampilkan dalam bentuk GUI. Selain itu juga menggunakan Secure Shell (SSH) yang akan dijadikan penguji untuk mengakses Router setelah metode Port Knocking dikonfigurasikan pada Mikrotik RB941-2ND.

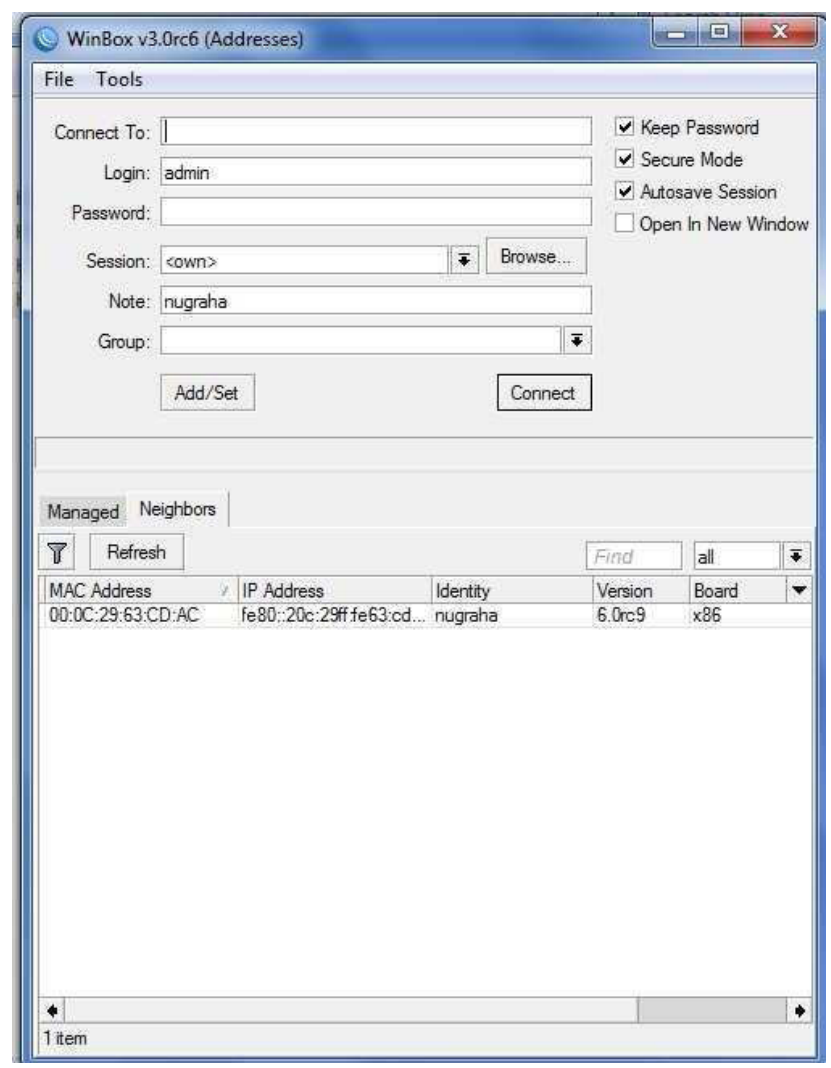

Gbr.3 Tampilan awal software Winbox-3 RC6

3. Perbandingan Sistem Berjalan dengan Sistem Usulan Ada beberapa perbedaan dari sistem berjalan dengan sistem yang akan diusulkan, berikut table perbedaan dari kedua sistem tersebut.

TABEL 3

PERBANDINGAN SISTEM BERJALAN DENGAN USULAN.

\begin{tabular}{|c|c|c|c|}
\hline No & Variabel & $\begin{array}{l}\text { Sistem } \\
\text { Berjalan }\end{array}$ & Sistem Usulan \\
\hline 1 & Hardware & $\begin{array}{l}\text { Modem } \\
\text { Fiberhome }\end{array}$ & $\begin{array}{l}\text { Penambahan Mikrotik } \\
\text { Routerboard }\end{array}$ \\
\hline 2 & Metode & Tidak Ada & Port Knocking \\
\hline 3 & Kelebihan & $\begin{array}{l}\text { Konfigurasi } \\
\text { sederhana }\end{array}$ & $\begin{array}{l}\text { Untuk mengakses Port } \\
\text { menggunkan autentikasi } \\
\text { knocd atau ketukan yang } \\
\text { telah ditentukan, saat } \\
\text { dimanage sistem menutup } \\
\text { port, sehingga tidak ada } \\
\text { yang bias mengkases sistem. }\end{array}$ \\
\hline
\end{tabular}

4. Kekurangan Port pada sistem jaringan terbuka, sehingga member kesempatan untuk di akses. Membutuhkan waktu lebih lama untuk mengakses sistem, karena menggunakan autentikasi.

\section{Rancangan Aplikasi}

Setelah melakukan analisa dan mengusulkan sistem yang akan digunakan, maka tahap selanjutnya ialah melakukan perancangan sistem yang diusulkan tersebut. 
1. Perancangan Konfigurasi hardware

Pada tahap ini dirancangan bagaimana hardware dapat saling terhubung secara fisik, sehingga semua hardwre dapat terkoneksi antara stu dengan yang lainya secara jaringan Local Area Network (LAN).

2. Perancangan IP Address Sistem Jaringan.

Berikut merupakan table IP Address untuk setiap Ether pada Mikrotik RB941-2ND dan hadware pendukung system jaringan.

TABEL 4

TABEL RANCANGAN IP ADDRESS

\begin{tabular}{|c|c|c|c|c|}
\hline Device & Interface & Ip Address & $\begin{array}{c}\text { Subnet } \\
\text { Mask }\end{array}$ & Gateway \\
\hline $\begin{array}{l}\text { Mikrotik } \\
\text { Routerboard } \\
\text { RB941-2nd }\end{array}$ & Ether 1 & 192.168 .88 .1 & $\begin{array}{l}255.255 .25 \\
5.0\end{array}$ & N/A \\
\hline $\begin{array}{l}\text { Mikrotik } \\
\text { Routerboard } \\
\text { RB941-2nd }\end{array}$ & Ether 2 & 192.168 .88 .2 & $\begin{array}{l}255.255 .25 \\
5.0\end{array}$ & N/A \\
\hline $\begin{array}{c}\text { PC } \\
\text { Manager }\end{array}$ & $\begin{array}{l}\text { Wireless } \\
\text { Adapter }\end{array}$ & 192.168 .88 .3 & $\begin{array}{l}255.255 .25 \\
5.0\end{array}$ & $\begin{array}{l}192.168 .88 . \\
2\end{array}$ \\
\hline PC Admin & $\begin{array}{l}\text { Wireless } \\
\text { Adapter }\end{array}$ & 192.168 .88 .4 & $\begin{array}{l}255.255 .25 \\
5.0\end{array}$ & $\begin{array}{l}192.168 .88 . \\
2\end{array}$ \\
\hline PC Media & $\begin{array}{l}\text { Wireless } \\
\text { Adapter }\end{array}$ & 192.168 .88 .5 & $\begin{array}{l}255.255 .25 \\
5.0\end{array}$ & $\begin{array}{l}192.168 .88 . \\
2\end{array}$ \\
\hline PC Sales & $\begin{array}{l}\text { Wireless } \\
\text { Adapter }\end{array}$ & 192.168 .88 .6 & $\begin{array}{l}255.255 .25 \\
5.0\end{array}$ & $\begin{array}{l}192.168 .88 . \\
2\end{array}$ \\
\hline
\end{tabular}

3. Perancangan Konfigurasi Bridge mode pada Modem ADSL

Perancangan konfigurasi Bridge mode dilakukan untuk merubah mode modem ADSL menjadi mode Bridge, sehingga modem dapat digunakan sebagai Bridge oleh Mikrotik untuk mendapat jaringan internet Dan modem tidak lagi berfungsi sebagai media pengatur dalam jaringan, karena pengaturan dan konfigurasi jaringan dilakukan di Mikrotik BR941-2ND.

4. Perancangan Mikrotik sebagai PPPoE

Mikrotik akan dihubungkan dan dikonfigurasikan dengan Modem Fiberhome terlebih dahulu,sehingga menjadi PPPoE Client. Dan nanti dapat dikonfigurasikan dengan berbagai hardware yang mendukung sistem jaringan.

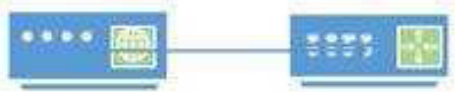

\section{Modem ADSL Mikrotik RB951UI-ND}

Gbr.4 Gambaran Modem ADSL dan Mikrotik

5. Perancangan Mikrotik sebagai Router Gateway

Perancangan ini diperlukan agar modem berfungsi sebagai Gateway untuk bagi client untuk mengakses internet. Dengan asumsikan Mikrotik RB941-2ND IP Address pada Ether1 :192.168.88.1 untuk terhubung ke internet dan IP Address pada Ether2 : 192.168.88.2, untuk client yang terhubug ke Mikrotik RB941-2ND.
6. Perancangan Port Knocking pada Mikrotik Routerboard Caranya adalah dengan memblok port HTTP (80), Telnet (23), dan SSH (22) dan ketika user ingin mengakses di mikrotik maka harus mengirimkan paket berupa ping ke IP adrdress Mikrotik Routerboard agar port 22 (SSH) tersebut dibuka, sehingga Secure Shell dapat mengakses Mikrotik Rb941-2ND.

Adapun gambaran dari perancangan penggunaan metode Port Knocking pada Mikrotik Routerboard 941-2ND sebagai berikut:

a. User melakukan Ping ke IP Addess Router 192.168.88.1. Dan Mikrotik RB941-2 ${ }^{\text {ND }}$ akan menyimpan IP tersebut selama 60 detik.
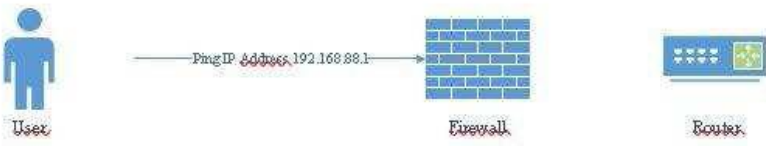

Gbr.5 User Melalukan Ping

b. User mencoba akses IP Address Mikrotik 192.168.88.1 melalui HTTP atau Browser dengan selang waktu maksimal 60 detik dari Ping sebelumnya, dan router akan mengecek apakah IP Address user tersebut apakah sama dengan yang sebelumnya.
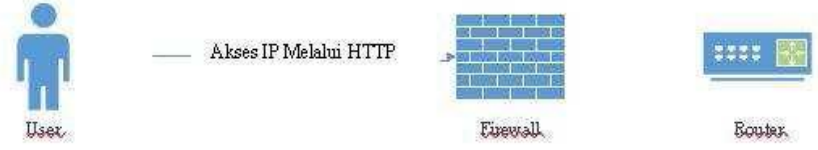

Gbr.6 User akses IP melalui HTTP

c. Dan jika IP Address sama dan waktu kurang dari 60 detik, maka IP tersebut di perbolehkan mengakses Port 22 (SSH) Mikrotik RB941- 2ND.

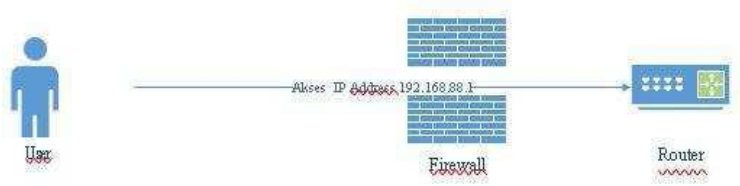

Gbr.7 User berhasil membuka port $22 \mathrm{SSH}$

Jika telah berhasil mengakses Mikrotik RB941-2ND, maka akan muncul tampilan login ke Mikrotik Routerboard, dan metode yang dikonfigurasikan pada Mikrotik tersebut telah berjalan dengan sukses.

E. Pengujian Jaringan

1. Pengujian Jaringan Awal

a. Konfigurasi Hardware

Pengujian awal ialah konfigurasi dari hardware pada jaringan sehingga saling terkoneksi, baik dari modem ADSL ke Mikrotik Rb941-2ND dan dari Mikrotik ke PC atau Client. 
b. Konfigurasi Mode Bridge pada modem ADSL

Pada gambar 1 dijelaskan langkah - langkah untuk merubah modem ADSL dari mode Modem menjadi mode Bridge, sehingga Mikrotik Routerboard menjadikanya sebagaijembatan untuk mendapatkan jaringan internet.

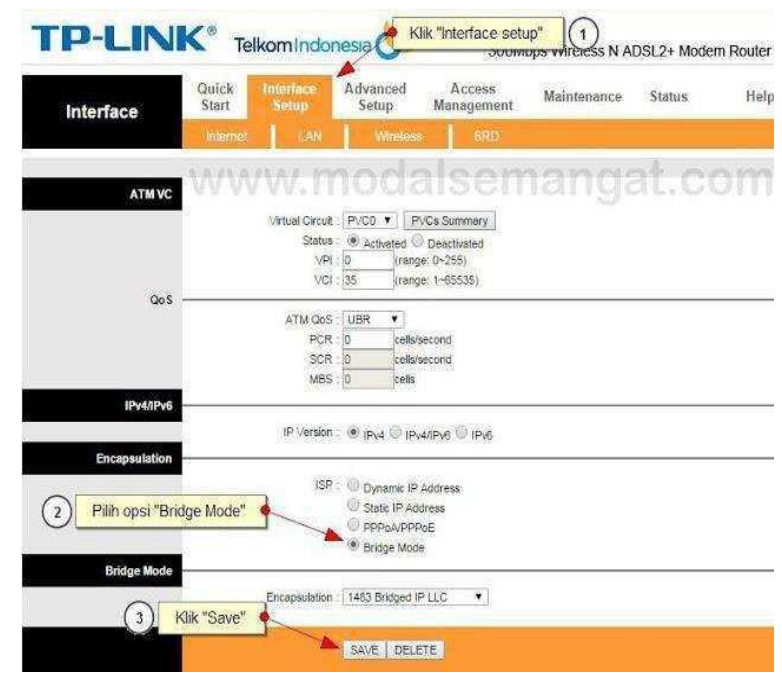

Gbr.8 Merubah Mode ModemADSLmenjadi Mode Bridge

Ada pun langkah-langkah merubah mode pada modem ADSL sebagaiberikut :

1) Buka browser dan ketik IP modem indihome Anda (192.168.1.1) dengan login user admin pass admin.

2) Klik "Interface Setup" kemudian "Internet"

3) Pada opsi "ISP" pilih "Bridge Mode"

4) Klik "Save"

c. Konfigurasi Jaringan Mikrotik sebagai PPPoE

Modem ADSL dan Mikrotik Router dihubungkan menggunakan kabel Straight, dan ada pun langkah langkahnya sebagai berikut :

1) Pastikan kabel Straight telah terpasang dari laptop ke Router

2) Login ke Mikrotik menggunakanWinbox

3) Klik menu "PPP"

4) Klik add / + pada tab "Interface" untukmenambahkan

5) Pilih "PPPoE Client"

6) Pada kolom name, rename dengan nama Indihome yang digunakan

7) Pada opsi "Interface" pilih interface/port mikrotik yang terhubung dengan modem ADSL

8) Klik tab "Dial Out"

9) Isi dengan nama user modem ADSL "Username"

10) Isi password pada kolom "Password"

11) Klik "Apply" atau "OK"
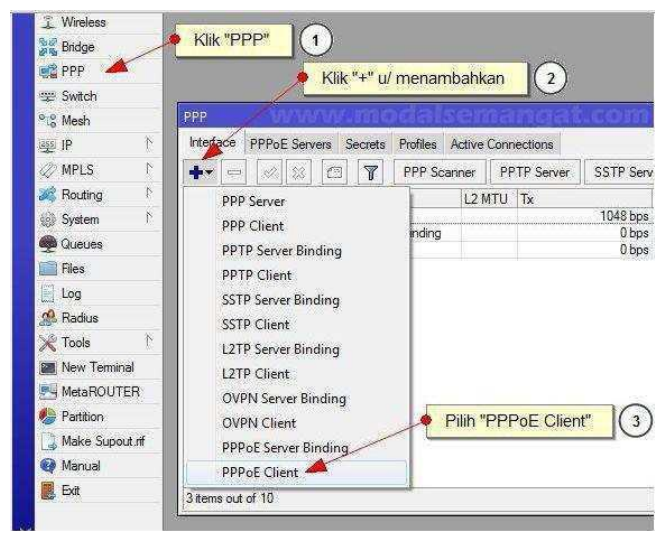

Gbr.9 Mikrotik Sebagai PPPoE Client

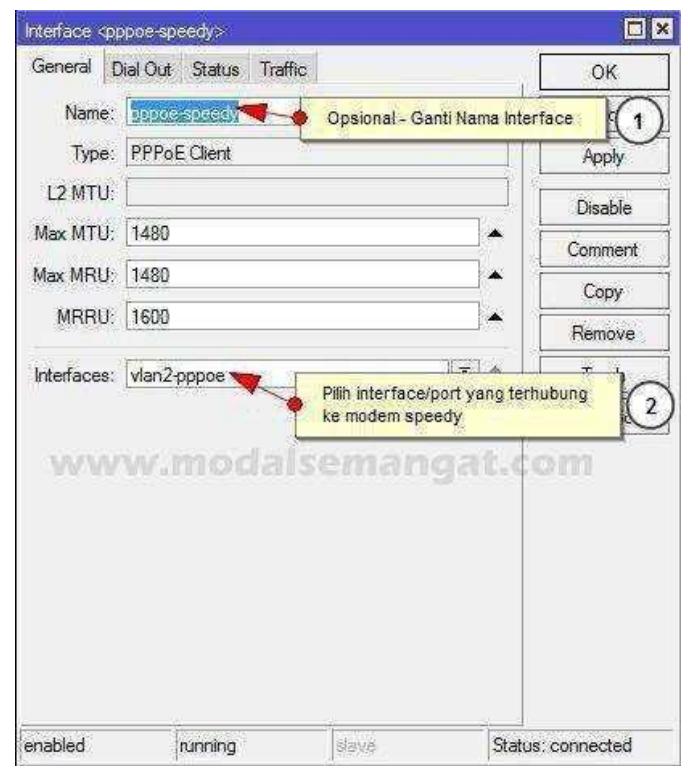

Gbr.10 Gambar Konfigurasi PPPoE



Gbr.11 Tahap akhir konfigurasi PPPoE 
Jika telah terkonfigurasi maka status interface akan menjadi connected, Maka mikrotik sudah terkoneksi ke modem ADSL.

D. Konfigurasi Mikrotik sebagai router gateway internet.

Langkah - langkah konfigurasi mikrotik sebagai Gateway sebagai berikut :

1) Berikan IP address terhadap masing-masingethernet pada mikrotik, sebagai berikut:

a) Ether 1: 192.168.88.1/24

b) Ether2: 192.18.88.2/24

2) Buka Mikrotik melalui Winbox

3) Klik menu "IP" kemudian pilih “Addresses".Lalu klik tanda add"+", masukan IP address dan pilih ethernet yang digunakan untuk IP address tersebut.



Gbr.12 Add IP Address

4) Tambahkan gateway tujuannya adalah menentukan IP mana yang akan menghubungkan ke internet. Menu "IP" pilih "Routes". Kemudian klik tombol add "+", dan masukan gateway nya. Pada contoh ini, IP 192.168.88.1 yang jadikan gateway, karena IP tersebut yang terhubung ke internet.

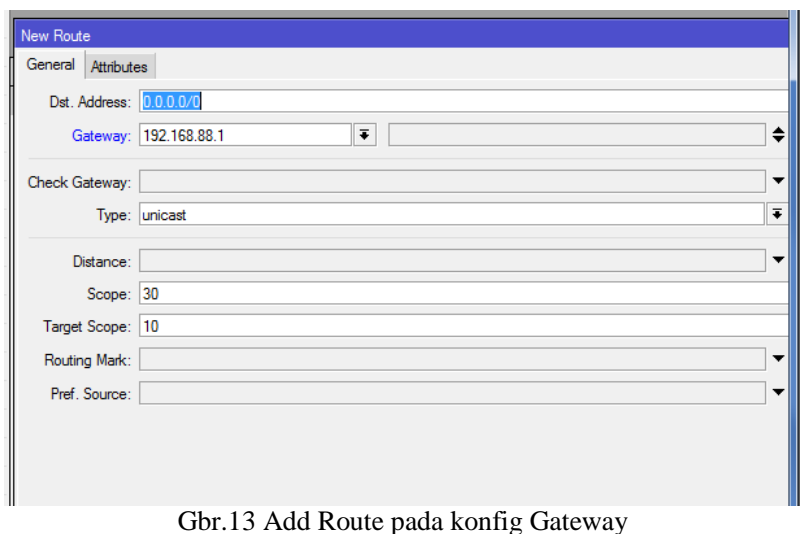

5) Kita tambahkan juga DNS. Singkat saja, fungsi DNS ini adalah untuk menerjemahkan nama domain kealamat IP, dan juga sebaliknya. Caranya pada menu "IP" pilih "DNS". Dan masukan IP-nya pada form servers.

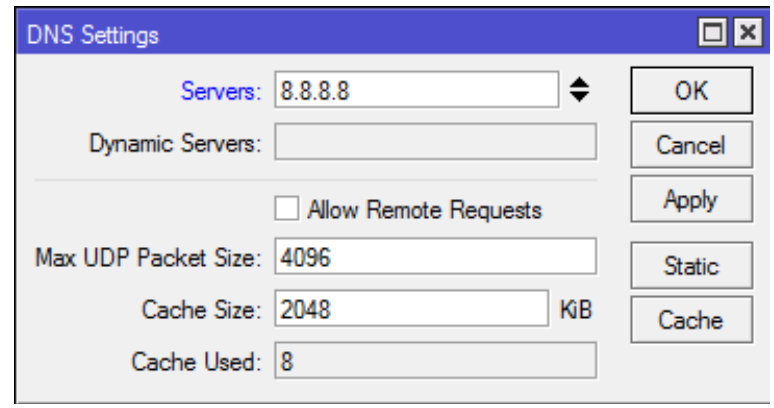

Gbr.14 Penambahan DNS Mikrotik

E. Konfigurasi Metode Port Knocking Pada Mikrotik

1) Login ke Mikrotik via Winbox.

2) Buat rule pertama, masukke Menu "IP" pilih "Firewall" pilihpada tab "Filter" Add $(+)$ rule

3) Pada tab "General"

a. Chain: input

b. Protocol: icmp

4) Pada tab "Action":

a. Action: add src to address list

b. Address List: ICMP

c. Timeout: 00:00:60

d. Apply "OK"

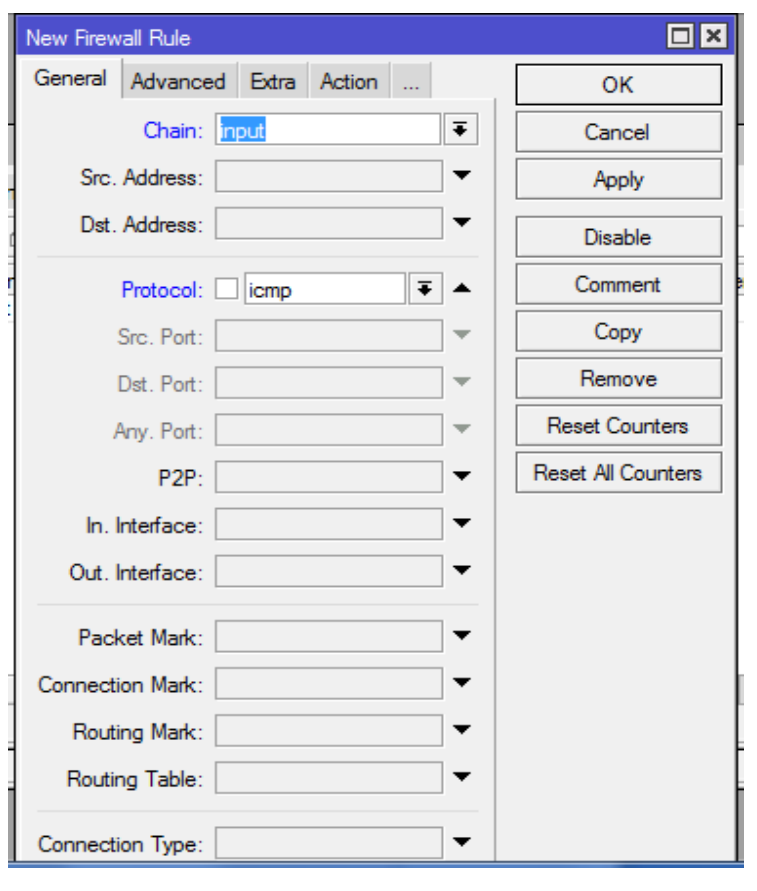

Gbr.15 Rule Pertama

5) Tambahkan rule kedua. Pada tab 'General':

a. Chain: input

b. Protocol: tcp

c. Dst. Port: 80

6) Pada tab "Advanced":

Src. Address List: ICMP 
7) Pada tab "Action":
a. Action: add src to address list
b. Address List: ICMP+HTTP
c. Timeout: 00:01:00

8) Buat rule ketiga agar Mikrotik dapat mengenali mengirimkan paket berupa ping untuk membuka port.

9) Pada tab "General":
a. Chain: input
b. Protocol: tcp
c. Dst. Port: 22,80

10) Pada tab "Advanced":

Src. Address List: !ICMP+HTTP

11)Pada tab "Action":
a. Action: Drop

\begin{tabular}{|c|c|c|c|c|c|c|c|c|c|}
\hline Firewall & & & & & & & & & 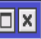 \\
\hline Filter Rul & des NAT Mangle Ra & Raw Service P & Ports Connect & ctions Address Lists & Layer7 Prc & tocols & & & \\
\hline+ & \& $\approx$ & $8: \approx$ Resel & et Counters & 00 Reset All Counter & & & Find & all & $\overline{+}$ \\
\hline$\#$ & Action Chain & Sic. Address & Dst. Address & S Proto... Src. Port & Dst. Port & In. Inter.. & Out. Int. & Bytes & $F \nabla$ \\
\hline 0 & प् add... input & & & 1 lic... & & & & $240 \mathrm{~B}$ & \\
\hline 1 & تt add... input & & & 6 (tcp) & 80 & & & $152 \mathrm{~B}$ & \\
\hline 2 & $X$ drop input & & & 6 (tcp) & 80,22 & & & $304 \mathrm{~B}$ & \\
\hline
\end{tabular}

Gbr.16 Susunan Rule Dari Metode

\section{Pengujian Jaringan Akhir}

Pada tahap ini dilakukan pengujian sistem yang diimplementasikan dengan proses langkah- langkah :

a. Lakukan Ping IP Address Mikrotik RB941-2ND.

b. Lakukan percobaan login ke IP Address Mikrotik melalui HTTP atau Browser.

c. Selanjutnya lakukan login melalui Secure Shell (SSH)

d. Jika langkah-langkah telah sesuai dengan rule maka Secure Shell akan dapat mengakses Mikrotik RB941-2ND.

\section{Hasil Pengujian}

a. Hasil Pengujian Mikrotik sebagai gateway

Setelah dikonfigurasikan Mikrotik BR941-2ND sebagai Gateway, sehingga setiap client dapat terhubung ke internet melalui dengan Mikrotik BR941-2ND sebagai gateway.

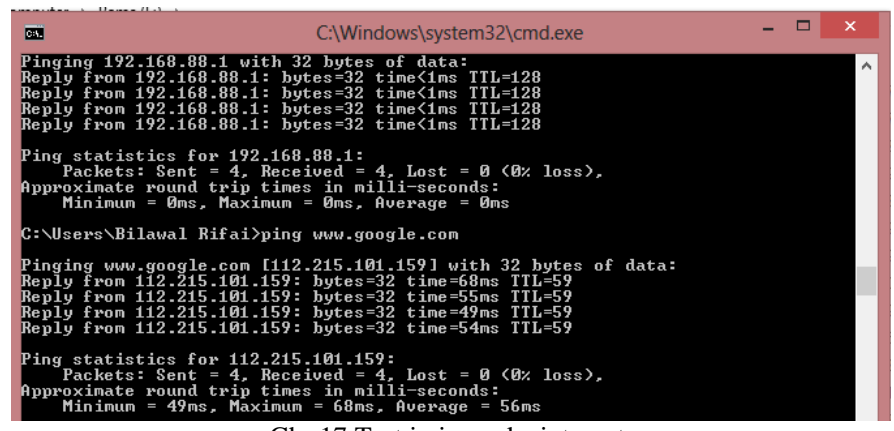

Gbr.17 Test jaringan ke internet

Ping ke google berhasil, dan ini menunjukan kalau jaringan mikrotik telah terhubung ke internet. b. Hasil Metode Port Knocking pada Mikrotik

Hasil implementasi diuji dengan mencoba akses Mikrotk RB941-2ND melalui SSH (22) tanpa ping terlebih dahulu ke IP Address Mikrotik, dan hasilnya akses ke Mikrotik gagal karena port tertutup.

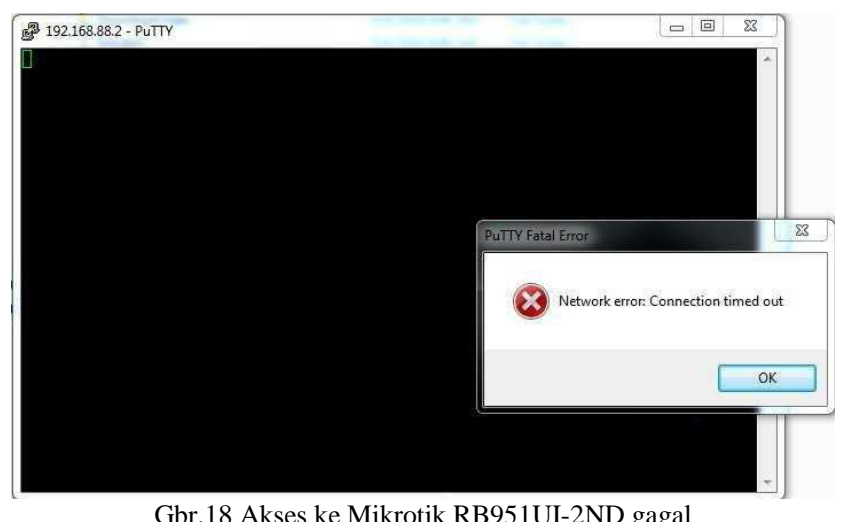

Selanjutnya dilakukan ping terlebih dahulu ke IP Address Mikrotik RB941-2ND 192.168.88.1

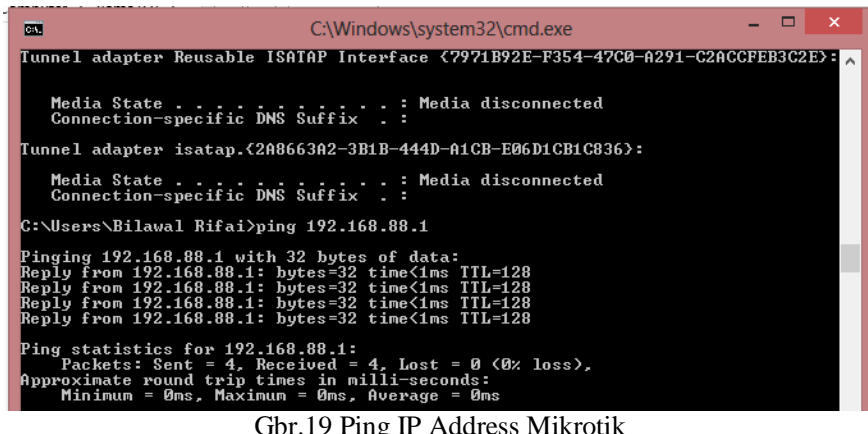

Dan setelah ping IP Address Mikrotik, dengan menggunakan Winbox langsung diakses kembali Mikrotik RB951UI-2ND dan ternyata berhasil masuk Mikrotik dengan tanpilan GUI pada Winbox.



Gbr.20 Berhasil akses Mikrotik RB941-2ND melalui SSH

Setelah melakukan Ping terlebih dahulu ke IP Address Mikroti RB941-2ND. Maka akses Router melalui SHH (22) dapat di kases, dengan tampilan awal login ke Router. 


\section{PENUTUP}

\section{A. Kesimpulan}

Penggunaan metode Port Knocking pada sistem keamanan jaringan, dengan studi kasus Lazis Wahdah Islamiyah yang sebelumnya menggunakan modem Asymmetric Digital Subscriber Line (ADSL) dirubah menggunakan Mikrotik Rb941-2ND sangat membantu dalam meningkatkan keamanan dan membantu Administrator lebih aman pada saat melakukan setting di router pada sistem jaringan. Dengan menggunakan metode ini port pada jaringan untuk mengakses Mikrotik RB941-2ND tertutup atau diblok, tapi tetap bisa diakses jika terlebih dahulu mengirim paket berupa Ping ke IP Address Mikrotik RB941-2ND.

\section{B. Saran}

Metode Port Knocking pada Mikrotik RB941-2ND pada sistem jaringan Lazis Wahdah Islamiyah sudah cukup baik, penyusun memberi saran agar sistem keamanan ini dikembangkan kedepanya seperti penggunaan metode ini untuk sistem jaringan dari kantor pusat ke cabang-cabang Lazis baik dengan menggunakan Telnet (21) atau Scure Shell (23) sebagai perangkat pendukung metode Port Knocking.

\section{UCAPAN TERIMA KASIH}

Penulis mengucapkan terima kasih kepada tim jurnal yang telah memberikan kesempatan pada penulis untuk menerbitkan penelitian ini pada jurnal teknik informatika (JTI) STMIK Antar Bangsa.

\section{REFERENSI}

[1] Y. Sopyan, "Blokir Akses ke Login Modem Indihome dan Login Access Point di Mikrotik," 13 Oktober 2019. [Online]. Available: https://labkom.co.id/mikrotik/blokir-akses-ke-loginmodem-dan-login-access-point-di-mikrotik. [Accessed 13 Oktober 2019].

[2] M. S. H. Fajri, R. Suhatman and Y. E. Putra, "Analisa Port Knocking Pada Sistem Operasi Linux Ubuntu Server 12.04 LTS," Aksara Komputer Terapan, vol. II, 2013.

[3] D. Y. KRISTIANTO, "Keamanan Jaringan Menggunakan Firewall Dengan Metode Random Port Knocking Untuk Koneksi SSH," 1 Oktober 2015. [Online]. Available: https://sinta.unud.ac.id/uploads/wisuda/1108605024-1Halaman\%20Awal.pdf.

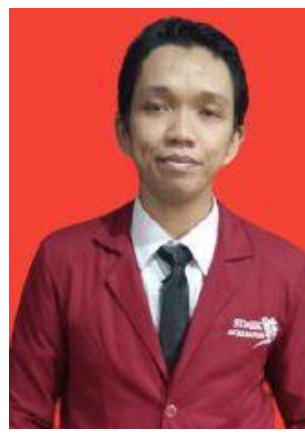

Ismanto. Lahir pada Tanggal 20 Mei 1988. Tahun 2020 lulus dari Program Strata Satu (S1) Program Studi Teknik Informatika di STMIK Antar Bangsa. Saat ini bekerja sebagai karyawan di Daarul Qur'an Shop (DAQU Shop)

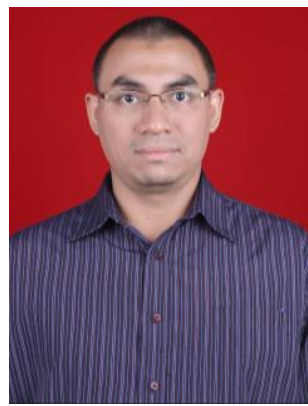

Aristejo, lahir di Jakarta pada tanggal 14 Oktober 1978. Tahun 2001 Lulus Sarjana Strata Satu (S1) Jurusan Teknik Sipil dari Universitas Trisakti. Tahun 2004 lulus Program Pasca Sarjana Fakultas Ilmu Komputer di Universitas Indonesia. Saat ini aktif mengajar sebagai dosen tetap program studi Teknik Informatika di STMIK Bangsa. 